\title{
Renin and angiotensin levels in children
}

\author{
FIONA BROUGHTON PIPKIN, OLIVER R C SMALES, AND MICHAEL J O'CALLAGHAN \\ Department of Obstetrics and Gynaecology, City Hospital, Nottingham, and Nottingham Children's Hospital
}

\begin{abstract}
SUMMARY Plasma renin activity, plasma renin concentration, and angiotensin II levels were measured in 63 normal children aged between 2 months and 12 years. The results showed that the high levels of renin and angiotensin II present in infancy remained above adult levels throughout the first decade of life but that there was a decline with age. Boys $<8$ years old had lower plasma renin activity and angiotensin II levels than girls of a similar age; this may be due to a relative substrate deficiency. Serum urea levels were inversely correlated with plasma renin activity in both sexes. A significant inverse relationship was found between both plasma renin activity and angiotensin II, and serum sodium in the girls; a similar, although not statistically significant, relationship was seen with plasma renin activity in the boys. An inverse correlation was found between plasma renin concentration and diastolic blood pressure for the group as a whole.
\end{abstract}

The human newborn has high levels of $\operatorname{renin}^{1-3}$ and angiotensin II (AII), ${ }^{4}$ the latter being inversely related to blood pressure during the first 11 days of life. ${ }^{4}$ In fetal and newborn animals the reninangiotensin system responds to the same stimulisuch as hypovolaemia and saline depletion-that activate the system in adults. ${ }^{5}$ Only recently was it shown that changes in blood volume activate the renin-aldosterone system in the human newborn. ${ }^{6}$ In the older child there is some information on renin levels ${ }^{7-10}$ but none relating simultaneously-measured AII to renin. Since AII is the major biological effector agent of the renin-angiotensin system we felt it would be worthwhile documenting the levels of renin and angiotensin in the normal child to determine the factors concerned in homeostasis.

\section{Materials and methods}

Twenty boys and 43 girls were studied. Each had been referred for intravenous pyelogram (IVP) for investigation of urinary infection, enuresis, or abdominal pain. Informed consent was obtained from the parent who accompanied the child.

The children had taken nothing by mouth since midnight. All measurements were made between 0900 and 1100 hours. All had a physical examination including measurement of supine blood pressure recorded from the right arm after 10-15 minutes' rest. The cuff used covered at least two-thirds of the upper arm. Urine microscopical examination and culture were carried out on each child. At the time of the IVP injection, with the child still supine, a $10 \mathrm{ml}$ venous blood sample was taken for estimation of blood urea and electrolytes, and for plasma renin activity (PRA), renin concentration (PRC), and AII. Blood for hormone measurements was placed immediately in a mixture of $0.125 \mathrm{~mol} / \mathrm{l}$ EDTA and $0.025 \mathrm{~mol} / \mathrm{l}$ o-phenanthroline.

PRA, PRC, and AII were measured as previously described. ${ }^{11}$ Briefly, for PRA measurement the sample was incubated in the presence of angiotensinase inhibitors, and the generated angiotensin I (AI) measured by radioimmunoassay. PRA is thus a measurement of the AI-generating capacity of the plasma under conditions of temperature and $\mathrm{pH}$ pertaining in vivo. PRC however, is a measurement of the total AI-generating capacity of the plasma at physiological $\mathrm{pH}$. The sample was incubated as above, in the presence of an excess of heterologous renin substrate, and the generated AI again measured by radioimmunoassay. AII levels were measured by radioimmunoassay after extraction from plasma on to an ion-exchange resin and subsequent elution with an ammonia:methanol mixture. ${ }^{4}$

For comparison, blood samples were obtained from 25 normotensive adult volunteers (men and women) aged between 18 and 34 , after at least 15 minutes in the supine position. Hormone estimations were carried out as above.

Haematocrit was measured using a Hawksley microhaematocrit centrifuge. Urea and electrolytes were measured using a Technicon SMA 660 system.

Arithmetical mean values are quoted \pm 1 standard 
error of the mean throughout. Student's $t$ test was used as appropriate to test for significance of difference between group means. Linear regression coeff.cients were calculated by the method of least squares. Multivariate regression analysis was performed using SPSS programmes ${ }^{12}$ on an IBM 1906A computer.

\section{Results}

No biochemical or radiographic abnormality was detected in 60 children.

Three girls were found to have minor variations in renal anatomy but as the micturating cystourethrogram in each was normal they were included in the study. Only 20 children were investigated with both an IVP and a micturating cystourethrogram. Minor degrees of reflux therefore, cannot be excluded in some of these children. Body weight and blood pressure were within 2 standard deviations of the mean for age in all children using normal standards. ${ }^{13} 14$ No significant differences were found between the boys and girls with respect to age, body weight, haematocrit values, blood pressure, serum sodium, or serum potassium (Table 1). Serum urea
Table 1 Age, weight, and some biochemical data (mean values + 1 SEM) in the children studied

\begin{tabular}{lrr}
\hline & \multicolumn{1}{c}{$\begin{array}{l}\text { Boys } \\
(n=20)\end{array}$} & \multicolumn{1}{c}{$\begin{array}{l}\text { Girls } \\
(n=43)\end{array}$} \\
\hline Age (years) & $8 \cdot 1 \pm 0 \cdot 6$ & $7 \cdot 3 \pm 0 \cdot 5$ \\
Weight (kg) & $26 \cdot 2 \pm 2 \cdot 0$ & $24 \cdot 4 \pm 1 \cdot 3$ \\
Haematocrit (\%) & $37 \cdot 1 \pm 0 \cdot 6$ & $37.8 \pm 0 \cdot 6$ \\
Systolic blood pressure (mmHg) & $101 \cdot 3 \pm 2 \cdot 4$ & $105 \cdot 6 \pm 2 \cdot 2$ \\
Diastolic blood pressure (mmHg) & $60 \cdot 0 \pm 2 \cdot 3$ & $64 \cdot 7 \pm 1 \cdot 8$ \\
Serum sodium (mmol/l) & $137 \cdot 5 \pm 0 \cdot 7$ & $137.9 \pm 0.4$ \\
Serum potassium (mmol/1) & $3 \cdot 9 \pm 0 \cdot 1$ & $4 \cdot 0 \pm 0 \cdot 1$ \\
Serum urea (mmol/l) & $4 \cdot 7 \pm 0 \cdot 2^{* *}$ & $3 \cdot 6 \pm 0 \cdot 2$ \\
\hline
\end{tabular}

$* * \mathbf{P}<0.001$.

Conversion: SI to traditional units-urea $1 \mathrm{mmol} / \mathrm{l} \approx 6 \mu \mathrm{g} / 100 \mathrm{ml}$.

levels however, although within the normal range, were significantly higher in the boys $(\mathrm{P}<0 \cdot 001)$.

PRA, PRC, and AII levels were all very much higher in the children than in the adults $(P \ll 0.001$ for all). Ranges and mean values are shown in Table 2. Table 3 gives hormone data for the children according to their gender. Mean PRA was slightly, but not significantly, higher in the girls; AII was significantly higher in girls $(\mathrm{P}<0 \cdot 002)$.

Both boys and girls could be subdivided into two roughly numerically-equal groups on the basis of

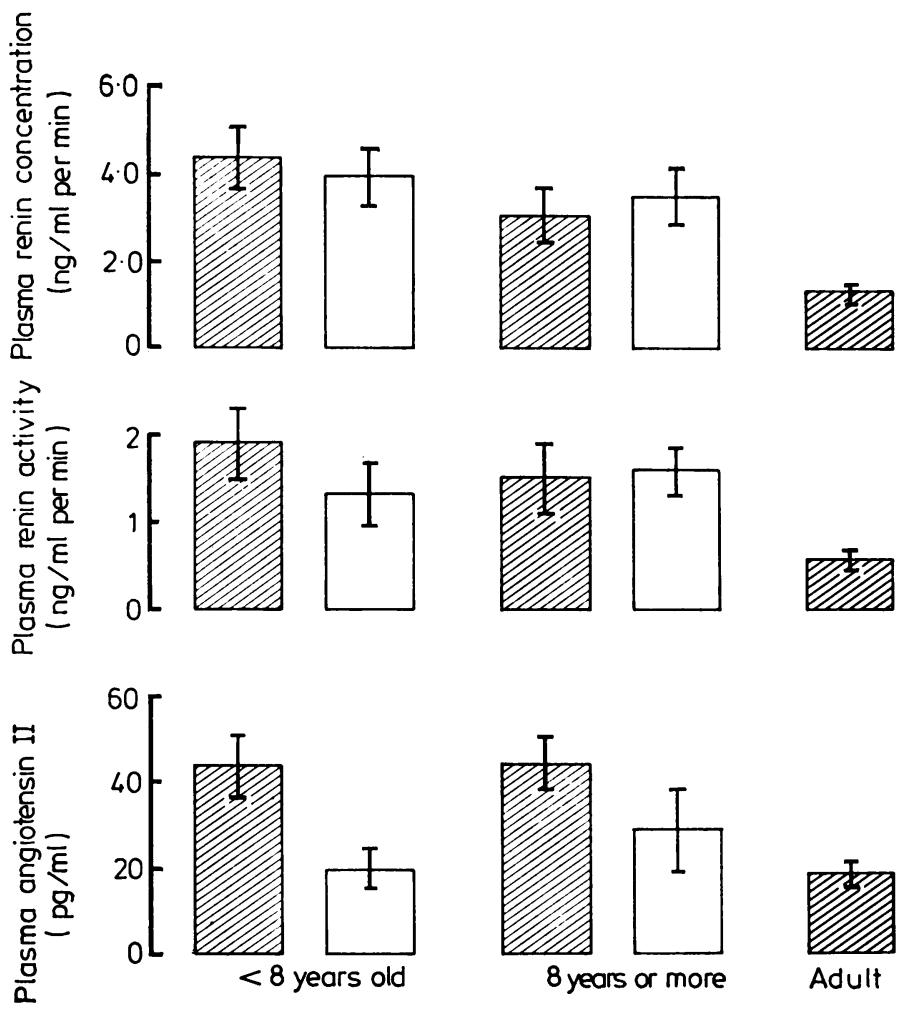

Conversion: traditional to SI units-angiotensin II: $1036 \mathrm{ng} / 1 \approx 1 \mathrm{pmol} / \mathrm{ml}$.

Figure Plasma renin concentration and plasma renin activity both fell with increasing age in girls (घ) while angiotensin II was unchanged. Plasma renin concentration fell slightly in the boys $(\square)$ but plasma renin activity and angiotensin II showed slight increases with age. 
Table 2 Comparison of mean values of components of the renin-angiotensin system in children and adults

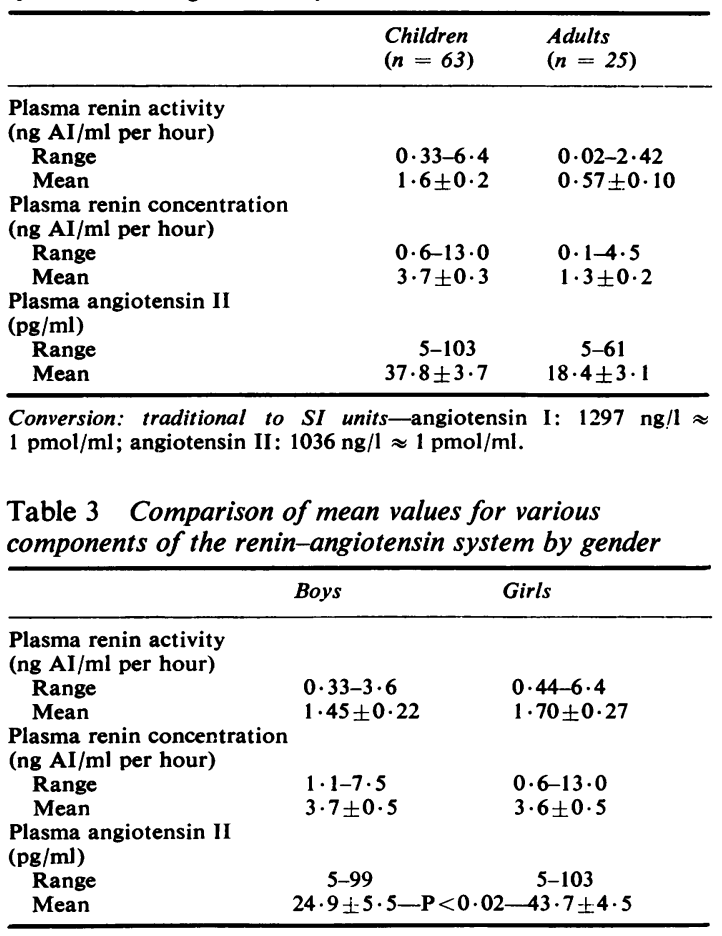

age - those $<8$ years, and those of 8 and more years. The Figure shows the hormone levels in the two groups of children according to gender, and in adults. PRC was essentially the same in both sexes in the younger children, PRA was somewhat lower in the boys $(\mathrm{P}<0 \cdot 7)$, and AII was significantly lower $(P<0.01)$. In the two older groups a similar trend was observed, but the difference did not reach statistical significance (Figure, $P>0.6$ for PRA, PRC, and AII).

Overall, in the girls both PRA and PRC fell significantly with increasing body weight $(\mathrm{P}<0.05$ for both); PRC also fell slightly with increasing weight in the boys but PRA and AII increased; these increases were not significant $(\mathrm{P}<0.8, \quad \mathrm{P}<0.3$ respectively).

Serum urea levels differed greatly between the two sexes, boys having a mean level of $4 \cdot 7 \pm 0.2 \mathrm{mmol} / 1$ $(28.2 \pm 1.2 \mathrm{mg} / 100 \mathrm{ml})$ while that in the girls was $3 \cdot 6 \pm 0 \cdot 2(21 \cdot 6 \pm 1 \cdot 2)(P<0 \cdot 001$; Table 1). This difference seemed to be unrelated to age or body weight. Urea levels were however, inversely correlated with PRA in both sexes $(\mathrm{P}<0.05$ for boys; $\mathrm{P}<0.025$ for girls). This inverse correlation was also apparent for PRC in the girls $(P<0.025)$. When partial correlation coefficients were calculated to exclude the effect of body weight, the inverse relationship was further strengthened in the boys $(P<0.002)$ and largely unchanged in the girls $(P<0.025)$. No correlation was found betweeen serum sodium or potassium and serum urea.

Plasma AII and PRA both showed a strong inverse correlation with serum sodium levels $(\mathrm{P}<0.005 ; \mathrm{P}<0.001$ respectively $)$ in the girls. $\mathrm{A}$ similar but not statistically significant correlation was found with PRA in the boys $(P<0 \cdot 7)$. Overall, serum sodium levels were directly correlated with body weight $(P<0.05)$ but calculation of partial correlation coefficients showed the inverse relationship between PRA or AII and serum sodium in the girls to be largely independent of body weight. No statistically significant relationship was found between any of the parameters measured and serum potassium levels.

In the children as a group, there was a significant inverse relationship between diastolic blood pressure and PRC $\quad(\mathrm{P}<0.05) ;$ a similar relationship approached significance between systolic blood pressure and $\operatorname{PRC}(0 \cdot 1<P>0.05)$.

\section{Discussion}

While a great deal of data now exists concerning PRA or PRC levels in children of the age range studied here, ${ }^{7-10}$ there has not been a study of simultaneously-measured PRA, PRC, and AII. Since AII is generally considered to be the major effector hormone of the system, it seemed to us to be of interest to establish interrelated baseline levels, especially in relation to plasma electrolytes.

The selection of children in a study of normal circulating hormones raises ethical difficulties. In this study the children were investigated according to clinical indications and the IVP injection merely provided the opportunity for blood sampling for research purposes. These children cannot be considered entirely normal in view of their presentation to hospital but the completeness of their documentation and absence of organic disease, demonstrable by radiographical or biochemical means, makes them a reasonable group for study.

Both PRA and PRC were higher in younger children (Figure) as has been previously reported. ${ }^{7-10}$ The very high levels seen in the first month or so of life ${ }^{1-3}$ may be stimulated by the lower blood pressures seen at this time, since hypotension is a potent stimulus for renin release. ${ }^{15}$ There is a sharp increase in systolic blood pressure during the first 6 days of extrauterine life $\mathrm{e}^{16}$ which is inversely correlated with plasma AII levels. ${ }^{4}$ The rate of increase then slows, although both systolic and diastolic blood pressure continue to increase until 14 or 15 years of age. ${ }^{14}$ 
Even in the large series of Londe, ${ }^{14}$ the correlation coefficients were weak, so it is probably not surprising that in our smaller series, statistically significant correlations between age and blood pressure were not found. However, children older than $\mathbf{8}$ years did have significantly higher systolic and diastolic blood pressures than younger children $(\mathrm{P}<0.001, \mathrm{P}<0.05)$. Thus the observed fall in renin levels with increasing age might be partly related to this increase in blood pressure. ${ }^{15}$ This hypothesis is supported by the finding of a weak, but statisticallysignificant inverse correlation between diastolic blood pressure and PRC in the group as a whole.

Another extremely potent stimulus for renin release is a low serum sodium concentration. ${ }^{15}$ We found that serum sodium increased with increasing body weight, and was inversely related to both PRA and AII in girls, and to PRA in boys. Children of this age can respond to sodium restriction with an increase in PRA. ${ }^{17}$ It thus seems very likely that the progressive fall in PRA and PRC with age may also be related to increasing maturity of renal function with the attainment of adult serum sodium levels. In the newborn, as in patients with Bartter's syndrome, fractional proximal tubular sodium reabsorption is reduced compared with normal adults. The high renin levels both in young children and in Bartter's syndrome may thus be exerting a homeostatic effect, not only by increasing systemic blood pressure but possibly also by their effects in limiting glomerular plasma flow and filtration rate.

Serum potassium levels are correlated with PRA in children 3-12 months of age. ${ }^{18}$ However, mild potassium depletion in 6- to 12-year-old children failed to alter PRA levels although urinary aldosterone excretion was suppressed. ${ }^{19} \mathrm{We}$ also failed to find statistically significant correlations between components of the renin-angiotensin system and serum potassium levels, although there appeared to be trends relating PRA, PRC, and AII to serum potassium. This tends to confirm the results of Broyer and Rizzoni, ${ }^{19}$ that the main effect of the potassium ion is a direct action on aldosterone secretion, rather than via the renin-angiotensin system.

The differences with gender in the younger children are interesting and have not previously been noted. PRC is a measure of the total AI-generating capacity of a plasma sample in the presence of excess substrate, while PRA measures the AI-generating capacity of the plasma sample as it stands and thus depends both on substrate and renin levels. In these children, although PRC levels were the same in both sexes, PRA and AII were somewhat lower in the boys. This presumably reflects a relative deficiency of substrate, which is considered to be rate-limiting under normal circumstances, at least in the adult. ${ }^{22}$
While levels at birth are lower than those in maternal plasma, ${ }^{2}$ they are nevertheless much higher than those in normal adults, and remain high until at least 6 weeks after birth. ${ }^{2}$ These high renin substrate levels presumably contribute to the overall high PRA observed in children but measurements of renin substrate concentration in children of various ages have not been made.

The significantly higher blood levels of urea in the boys were unexpected, although all were within the normal range. Plasma creatinine concentrations have previously been found to be somewhat higher in boys than girls ${ }^{20}$; the same paper also showed a similar tendency for plasma urea concentrations to be higher in boys. Plasma creatinine concentrations were not measured in the children reported here.

The inverse relationship between blood urea and renin levels obtained regardless of gender. These children had all been referred for IVP with suspected renal abnormalities and although none was found, the possibility exists of minor parenchymal renal damage not identified by IVP. Raised PRA has been reported in children with pyelonephritic scarring ${ }^{21}$ and no evidence of renal impairment.

It is of interest that AII levels remained high over the period of study, despite decreasing PRA and PRC levels. Little is known of either converting enzyme activity or angiotensinase levels at this age, either of which can greatly affect final AII concentrations. The maintenance of high AII levels up to at least 12 years of age should be borne in mind when assessing possible clinical malfunction of the renin-angiotensin system.

In conclusion, we have established basal means and ranges for simultaneously-measured PRA, PRC, and AII in 63 apparently normal children and have attempted to relate them to stimuli known to affect the renin-angiotensin system in the adult. The high levels of PRA, PRC, and AII in these children appear to be related both to their lower blood pressures, and possibly more importantly, to their serum sodium levels.

We thank the consultant paediatric staff of the City Hospital and Children's Hospital, Nottingham, for allowing us access to patients under their care, and Miss C Gledhill, Miss D Kirby, Mrs A Warren, and Mr T Newton for skilled technical assistance.

\section{References}

1 Krause D K, Schillmöller U, Hayduk K. Erhöhte Plasma-Renin-Konzentration bei gesunden Säuglingen, Klein-und Schulkindern im Vergleich zu erwachsenen Normalpersonen. Dtsch MedWochenschr 1972; 97: 1133-4. 
${ }^{2}$ Kotchen T A, Strickland A L, Rice T W, Walters D R. A study of the renin-angiotensin system in newborn infants. J Pediatr 1972; 80: 938-46.

3 Dillon M J, Gillin M E A, Ryness $\mathbf{J}$ M, de Swiet $\mathbf{M}$. Plasma renin activity and aldosterone concentration in the human newborn. Arch Dis Child 1976; 51: 537-40.

4 Broughton Pipkin F, Smales O R C. A study of factors affecting blood pressure and angiotensin II in newborn infants. J Pediatr 1977; 91 : 113-9.

5 Mott J C. The place of the renin-angiotensin system before and after birth. Br Med Bull 1975; 31 : 44-50.

- Dillon M J, Rajani K B, Shah V, Ryness J M, Milner R D G. Renin and aldosterone response in human newborns to acute change in blood volume. Arch Dis Child 1978; 53: 461-7.

7 Dillon M J, Ryness J M. Plasma renin activity and aldosterone concentration in children. $B r$ Med J 1975; iv: 316-9.

8 Sassard J, Sann L, Vincent M, François R, Cier J F. Plasma renin activity in normal subjects from infancy to puberty. J Clin Endocrinol Metab 1975; 40: 524-5.

9 Stalker H P, Holland N H, Kotchen J M, Kotchen T A. Plasma renin activity in healthy children. J Pediatr 1976; 89: 256-8.

10 Hiner L B, Gruskin A B, Baluarte H J, Cote M L. Plasma renin activity in normal children: its relationship to age and rates of excretion of sodium and potassium. $J$ Pediatr 1976; 89: 258-61.

11 Symonds E M, Broughton Pipkin F, Craven D J. Changes in the renin-angiotensin system in primigravidae with hypertensive disease of pregnancy. Br J Obstet Gynaecol 1975; 82: 643-50.

12 Nie N H, Bent D H, Hull C H. Statistical package for the social sciences. New York: McGraw Hill, 1970.

13 Tanner J M, Whitehouse R H, Takaishi M. Standards from birth to maturity for height, weight, height velocity, and weight velocity: British children, 1965. Arch Dis Child $1966 ; 41$ : 454-71.

14 Londe S. Blood pressure in children as determined under office conditions. Clin Pediatr (Phila) 1966; 5: 71-8.

15 Davis J O. The control of renin release. Am J Med 1973; 55: $333-50$.

16 De Swiet M, Fancourt R, Peto I. Systolic blood pressure variation during the first 6 days of life. Clin Sci Mol Med 1975; 49: 557-61.

17 Godard C, Riondel A M, Veyrat R, Megevand A, Muller A F. Plasma renin activity and aldosterone secretion in congenital adrenal hyperplasia. Pediatrics $1968 ; 41$ : 883-96.

18 Siegler R L, Crouch R H, Hackett T N, Jr, Walker M, Jubiz W. Potassium-renin-aldosterone relationships during the first year of life. J Pediatr 1977; 91 : 52-5.

19 Broyer M, Rizzoni G. Plasma renin activity and aldosterone excretion in normal children on mild potassium restriction. Biomedicine 1973; 18: 538-43.

20 Schwartz G J, Haycock G B, Spitzer A. Plasma creatinine and urea concentration in children: normal values for age and sex. J Pediatr 1976; 88: 828-30.

21 Savage J M, Dillon $M$ J, Shah V, Barratt $T$, Williams D I. Renin and blood pressure in children with renal scarring and vesicoureteric reflux. Lancet 1978; ii: 441-4.

22 Skinner S L, Lumbers E R, Symonds E M. Alteration by oral contraceptives of normal menstrual changes in plasma renin activity, concentration, and substrate. Clin Sci 1969; 36: 67-76.

Correspondence to Dr Fiona Broughton Pipkin, Department of Obstetrics and Gynaecology, City Hospital, Hucknall Road, Nottingham NG5 1PB.

Received 5 February 1980 